\title{
Synthesis and Characterization of Trimethylolpropane Based Esters as Green Biolubricant Basestock
}

\author{
Salma Samidin ${ }^{1}$, Nadia Salih ${ }^{2, *}$, Jumat Salimon ${ }^{3}$ \\ 1 Department of Chemical Sciences, Faculty of Science and Technology, Universiti Kebangsaan Malaysia, 43600 Bangi, \\ Selangor, Malaysia; salma_samidin@yahoo.com (S.S.); \\ 2 Department of Chemical Sciences, Faculty of Science and Technology, Universiti Kebangsaan Malaysia, 43600 Bangi, \\ Selangor, Malaysia; nadiaalnami@ hotmail.com (N.S.); \\ 3 Department of Chemical Sciences, Faculty of Science and Technology, Universiti Kebangsaan Malaysia, 43600 Bangi, \\ Selangor, Malaysia; jumatsal@gmail.com (J.S.); \\ * Correspondence: nadiaalnami@hotmail.com;
}

Scopus Author ID 24072094400

Received: 20.12.2020; Revised: 4.02.2021; Accepted: 8.02.2021; Published: 14.02.2021

\begin{abstract}
Bio-based lubricant is crucial to be developed considering the toxicity risk, climate change, energy security, and green-environmental approach. In this work, trioleate trimethylolpropane (TOTMP) (1) was synthesized through the esterification between trimethylolpropane (TMP) and oleic acid (OA) using a sulfuric acid catalyst. TOTMP was chemically modified to produce hyperbranched nonaoleate trimethylolpropane (NOTMP) (4). TOTMP was first epoxidized to epoxidized trioleate trimethylolpropane (ETOTMP) (2) followed by ring-opening reaction to produce trihydroxyhexaoleate trimethylolpropane (THHOTMP) (3). Lastly, THHOTMP was further esterified with OA to produce hyperbranched biolubricant NOTMP. Chemical structure confirmation of each product was performed by using Fourier transformation infrared (FTIR), proton, and carbon nuclear magnetic resonance $\left({ }^{1} \mathrm{H}\right.$ and ${ }^{13} \mathrm{C}$ NMR). The physicochemical analysis showed that the oxidative stability of NOTMP was at $172^{\circ} \mathrm{C}$, pour point at $-34^{\circ} \mathrm{C}$, flash point at $320^{\circ} \mathrm{C}$, and viscosity index at 237 . The tribology analysis showed good wear protection with a minimal decrease in the friction coefficient $(\mu)$. Furthermore, rheology analysis showed that all synthesized compounds had been classified as Newtonian fluids. Therefore all the branched esters' bio lubricant products were successfully produced with improved lubricity properties, which are plausible for bio lubricants for both tropical and temperate countries.
\end{abstract}

Keywords: hyperbranched; tribology and rheology analysis; lubrication properties; green biolubricant.

(C) 2021 by the authors. This article is an open-access article distributed under the terms and conditions of the Creative Commons Attribution (CC BY) license (https://creativecommons.org/licenses/by/4.0/).

\section{Introduction}

When two moving surfaces move against each other, friction will result. To reduce this friction, a lubricant is used. The lubricant helps reduce wear and loss arising from excessive friction. Lubricating oils have many functions as a sealant against dust, water, and dirt, as an insulator in transformers, and prevent rust and oxidation. Researchers are now looking to develop new biolubricants that would be less sensitive to temperature change, biodegradable, fluid at very low temperatures, less volatile, and more stable at very high temperatures [1-4]. Lubricants that are bio-based or plant-based are called biolubricants or bio-lubes. The base oil is usually a type of plant oil extracted from olives, palm, soybean, canola, rapeseed, castor beans, tallow, jojoba, or coconut [5]. 
Since biolubricants can biodegrade, the industry has now placed a lot of focus on researching biofuel's potential. Besides, biolubricants can also be renewed and are non-toxic and environmentally friendly [6,7]. It is now more important than ever to protect the environment and human beings by ensuring that biolubricants are produced, applied, and disposed of in a green manner. Direct contact between humans and biolubricants must be verified as safe. The best measures must be taken to minimize damage to the environment. One such approach is to weigh the benefits and risks associated with biolubricants to ensure environmental sustainability $[8,9]$.

However, since plant oil has low hydrolytic and thermo-oxidative stability and flows poorly in cold conditions, it is normally not directly applied as biolubricants. This is due to the glycerol backbone in the triacylglycerol structure of the plant oil, which consist of $\beta-\mathrm{H}$ atom on the middle carbon; this makes plant oil esters more susceptible to the elimination reaction leading to the subsequent degradation of the molecule, which is thermally unstable $[10,11]$.

This drawback can be mitigated via suitable modifications to the plant oil structure. Some approaches have been introduced to make plant oil properties more desirable. For example, plant oil is chemically modified to improve its lacking properties. Other times, antioxidants, viscosity modifiers, or pour point depressants are added to the plant oil. Still, other methods have attempted to genetically modify plant oils' fatty acid profile to achieve the same end $[12,13]$. Chemical modification has proven to be the most promising of all these methods, improving the plant oil's chemical structure so it remains stable across a wide temperature range. This method usually modifies the doubles bonds and functional groups (acyl and alkoxy) in the oil. The latest studies on chemical modification involved the improvement of $\beta$-H stability $[14,15]$.

In this study, the core compound of biolubricants was produced through TMP and OA's esterification reaction to produced trioleate trimethylolpropane (TOTMP) (1). TOTMP has a good performance as biolubricanting oils but still has low oxidative stability due to the double bond site at the fatty acid chain. Therefore, further chemical modification at the double bond site of TOTMP had been done by performing epoxidation and ring-opening reactions at the double site to produce the final product nonaoleate trimethylolpropane (NOTMP) (4).

\section{Materials and Methods}

\subsection{Chemicals.}

TMP 97\%, oleic acid 90\%, formic acid 88\%, sulphuric acid 99\%, and hydrogen peroxide 30\% were obtained from (Sigma Aldrich), (Merck, Germany), Fisher Scientific (Pittsburgh, PA, USA), SYSTERM, and (Merck, Germany), respectively. All of the chemicals and solvents were either analytical or high-performance liquid chromatography (HPLC) grade and used directly without further purification.

\subsection{Synthesis of trioleate trimethylolpropane (TOTMP), 1 .}

TMP (20 g) and OA (100 g) were mixed in the 3 neck glass reactor fixed with a magnetic stirrer. Sulphuric acid (1.5\%) was added to the mixture as a catalyst and heated the mixture to $150^{\circ} \mathrm{C}$ for 5 hours. Toluene $(100 \mathrm{ml})$ was added to the mixture of reactions as an azeotroping agent. The flask mouth was fitted with a Dean-Stark cap to carry out the azeotropic distillation of water-toluene. Samples were extracted using ethyl acetate and washed with brine solution before drying with anhydrous sodium sulfate. Trioleate trimethylolpropane (TOTMP) 
was dried using a vacuum rotary evaporator at $70^{\circ} \mathrm{C}$ and was analyzed by FTIR as a detection to the formation of functional groups.

\subsection{Synthesis of epoxidized trioleate trimethylolpropane (ETOTMP), 2.}

TOTMP (15 g) was added to the three-neck flask with formic acid 88\% equipped with a magnetic stirrer and a thermometer and heat for 3.5 hours. Hydrogen peroxide $30 \%$ was added slowly into the stirrer solution drop by drop within 60 minutes in total, and the reaction was held at constant temperature and under stirring for several hours. At the end of the reaction, the product was extracted with ethyl acetate, and the aqueous was eliminated, and the organic phase was then thoroughly washed with $5 \% \mathrm{NaHCO}_{3}$, and $5 \%$ saturated $\mathrm{NaCl}$ to neutral the acidity to $\mathrm{pH} 7$ and dried with anhydrous sodium sulfate for a night. The end of the oil's epoxidized product was isolated by rotary evaporation to remove the solvent used at $40^{\circ} \mathrm{C}$.

\subsection{Synthesis of trihydroxyhexaoleate trimethylolpropane (THHOTMP), 3.}

Oxirane ring-opening reaction was carried out using oleic acid as nucleophile reagents and $p$-toluene sulfonic acid (PTSA) as a catalyst. PTSA was added to the mixture of ETOTMP and oleic acid $90 \%$ (2-5 g). The mixture was heated with stirring 500-900 rpm at $120^{\circ} \mathrm{C}$ for 35 hours. When the reaction was complete, the products were purified with a base solution. The organic layer was dried over anhydrous sodium sulfate, filter, and the solvent was removed using a vacuum evaporator to give the desired product.

\subsection{Synthesis of nonaoleate trimethylolpropane (NOTMP), 4.}

About $5 \mathrm{~g}$ of THHOTMP was added with $2 \mathrm{~g}$ of oleic acid to the 3 neck glass reactor completed with a magnetic stirrer and temperature on silicon oil heated to the hot plate at the desired temperature. About $1.5 \%$ sulphuric acid is added to the mixture and heated to $120^{\circ} \mathrm{C}$ for 4 hours. The final product (NOTMP) was extracted with a non-polar solvent and wash with brine solution. After dry with sodium sulfate, the excess solvent was removed using a vacuum evaporator to give the desired product.

\subsection{Structural characterization analysis.}

Fourier transform infrared (FTIR) spectra were recorded on a Perkin Elmer GX FTIR Spectrophotometer (USA). The ${ }^{1} \mathrm{H}$ and ${ }^{13} \mathrm{C}$ analyses were recorded on a JEOL JNM-ECP 400 FTIR spectrometer $\left(400 \mathrm{MHz}^{1} \mathrm{H} / 100.61 \mathrm{MHz}{ }^{13} \mathrm{C}\right)$ using $\mathrm{CDCl}_{3}$ as a solvent in all experiments.

\subsection{Lubrication properties analysis.}

The synthesized compounds (1-4) should be tested to determine some aspects of the characterization to ensure that they are acceptable for use as biolubricants. Five main types of characterization were tested: viscosity index, pour point, flash point, oxidative stability, and tribological properties. Triplicate measurements were made, and the data was reported as a mean \pm SD of triplicate determinations.

\subsubsection{Viscosity and viscosity index (VI).}

A good biolubricant should have a moderate viscosity index (VI). The VI indicates the change in kinematic viscosity of a biolubricant with a temperature change. Essentially, the VI 
indicates the quality of the biolubricant. The automotive industry uses VI to characterize lubricating oils. The kinematic viscosity of the biolubricants in this study was measured using a rheometer model physics MCR 301, Anton Paar Instruments (Germany). The viscosity and VI were calculated according to ASTM method ASTM D 2270-04 [16].

\subsubsection{Pour point (PP).}

PP is defined as the lowest temperature at which a liquid can still be poured (still behaves like a fluid). Pour point values were measured according to the ASTM D97-05 method [17]. This method is routinely used to determine the low-temperature flow properties of fluids. For a greater degree of accuracy, PP measurements were carried out with a resolution of $1^{\circ} \mathrm{C}$ instead of the specified $3^{\circ} \mathrm{C}$ increments.

\subsubsection{Flash point (FP).}

FP is defined as the minimum temperature at which a heated volatile liquid vaporizes and ignites. FP was determined according to the ASTM D 56-79 method using a Tag Closed Tester [18].

\subsubsection{Oxidative stability.}

The lubricant oil oxidizes faster when it's exposed to oxygen at an elevated temperature. The quality of the oil reduces and turns more viscous. Pressure Differential Scanning Calorimetry (PDSC) model PDSC822e Metter Toledo was used to determine the oil's oxidative stability temperature (OST). The PDSC is a highly-selective device for evaluating the OST.

\subsubsection{Tribological and rheological properties.}

Interactions of the biolubricant with metal surfaces have dominance over the tribological performances. The performance of biolubricants under boundary conditions highly relies on their chemical structures. Assessments on esters' tribological properties were performed according to ASTM method D4172-94 [19], using Anton Paar rheometer (Anton Paar Physica MCR 301 model, Germany) with one ball geometry. The sliding speed was manipulated between $10^{-1}-10^{3} \mathrm{~mm} / \mathrm{s}$ at 40 and $100^{\circ} \mathrm{C}$ [20]. The synthesized compounds (1-4) were discussed based on their Stribeck curves at 40 and $100{ }^{\circ} \mathrm{C}$. Rheological properties were observed by the same rheometer with cone and plate geometry [21]. The cone spindle used was CP 25-2 with a diameter $0.051 \mathrm{~mm}$. The shear rate was manipulated between $0-100 \mathrm{~s}^{-1}$ at a temperature of $25^{\circ} \mathrm{C}$.

\section{Results and Discussion}

\subsection{Synthesis reactions.}

The synthesis of modified biolubricant containing nonaoleate within the trimethylolpropane derivatives was outlined in Figure 1. TOTMP (1) was yield with 98\% (w/w) from trimethylolpropane's esterification reaction with oleic acid. From this core biolubricants (TOTMP), further modification of biolubricant was made through the epoxidation and oxirane ring-opening reaction to produce epoxidized trioleate trimethylolpropane (ETOTMP) (2) and trihydroxyhexaoleate trimethylolpropane (THHOTMP) (3), respectively. Modification 
continued in esterified the resulting $\alpha$-hydroxyl group in THHOTMP with long-chain carbon of oleic acid to produce a new final biolubricant compound of hyperbranched nonaoleate trimethylolpropane (NOTMP) (4).

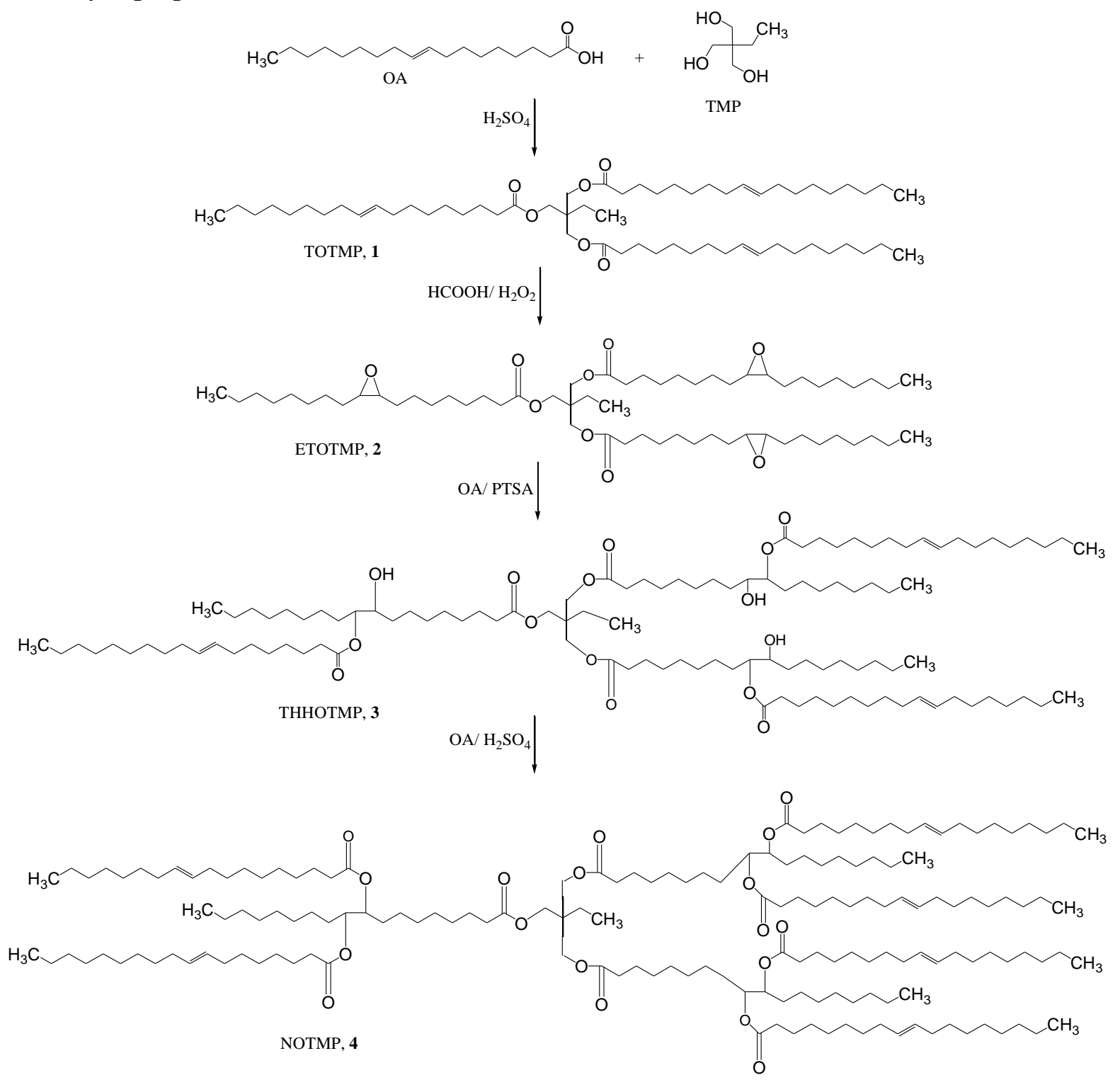

Figure 1. Synthesis scheme of compounds (1-4).

\subsection{Structural characterization analysis.}

FTIR spectra (Figure 2) of compounds (1-4) show the characteristic peaks of an ester at $1744,1743,1740$, and $1741 \mathrm{~cm}^{-1}$ indicating the ester $(\mathrm{C}=\mathrm{O})$ functional group. The FTIR spectrum for compound (2) shows the epoxy group's important peak at $824 \mathrm{~cm}^{-1}$, methylene inphase at $720 \mathrm{~cm}^{-1}$, methyl symmetric at peak $1386 \mathrm{~cm}^{-1}$, and methyl antisymmetric deformation at $1464 \mathrm{~cm}^{-1}$. For FTIR spectrum for compound (3), the important peak shows at $3002 \mathrm{~cm}^{-1}$ wavelength number of olefin $(\mathrm{HC}=\mathrm{CH})$ and the hydroxyl group's formation at $3448 \mathrm{~cm}^{-1}$. After further esterification of $\alpha$-hydroxyl with oleic acid, FTIR spectrum for compound (4) shows the invisible hydroxyl group at range $\left(\sim 2473-3450 \mathrm{~cm}^{-1}\right)$ [4].

All synthesized compounds were also verified by ${ }^{1} \mathrm{H}$ (Figure 3 ) and ${ }^{13} \mathrm{C}$ (Figure 4) NMR spectroscopy. The signals of compound (2) at $2.76 \mathrm{ppm}$ correspond to protons on the oxirane ring $(-\mathrm{CHOCH}-)$, while formations of new signal 1.48 and $1.51 \mathrm{ppm}$ correspond to allylic 
epoxy protons $\left(-\mathrm{CH}_{2} \mathrm{CHOCH}-\mathrm{CH}_{2}-\right)$ in which were absent in compound (1). From ${ }^{1} \mathrm{H}$ NMR spectra also show the disappearance of olefin protons at $5.3 \mathrm{ppm}$ for $\left(\mathrm{CH}_{2}=\mathrm{CH}_{2}\right)$ and allylic protons at 1.9 and $2.0 \mathrm{ppm}$ for $\left(-\mathrm{CH}_{2}-\mathrm{CH}=\mathrm{CH}-\mathrm{CH}_{2}-\right)$ [22]. For compound (3) (THHOTMP), the important signals that show the presence of hydroxyl group were an appearance at 3.19$3.58 \mathrm{ppm}$ and allylic hydrogen of $\mathrm{OH}$ group visible at $1.33-1.36 \mathrm{ppm}$.

The ${ }^{13} \mathrm{C}$ NMR spectra of compounds (1), (3), and (4) showed the chemical shifts of olefin at ( 129.7- $130.0 \mathrm{ppm})$, and there was no signal of olefin at the compound (2). The chemical shifts of carbon of epoxy (C-O-C) were readily visible at 57.03 and 57.08 ppm by comparing the spectra. The subsequently allylic carbons $\left(-\mathrm{CH}_{2}-\mathrm{CHOCH}-\mathrm{CH}_{2}-\right)$ appear at 27.7 and $27.8 \mathrm{ppm}$, respectively. For compound (3), the signal of carbon $\mathrm{C}-\mathrm{OH}$ was at $60.44 \mathrm{ppm}$. Furthermore, in the ${ }^{13} \mathrm{C}$ NMR spectra, the signals at approximately chemical shift $(\sim 173.27$, $173.25,174.11,173.49 \mathrm{ppm})$ for each compound are attributed to the ester carbonyl groups $\mathrm{C}=\mathrm{O}[23,24]$.

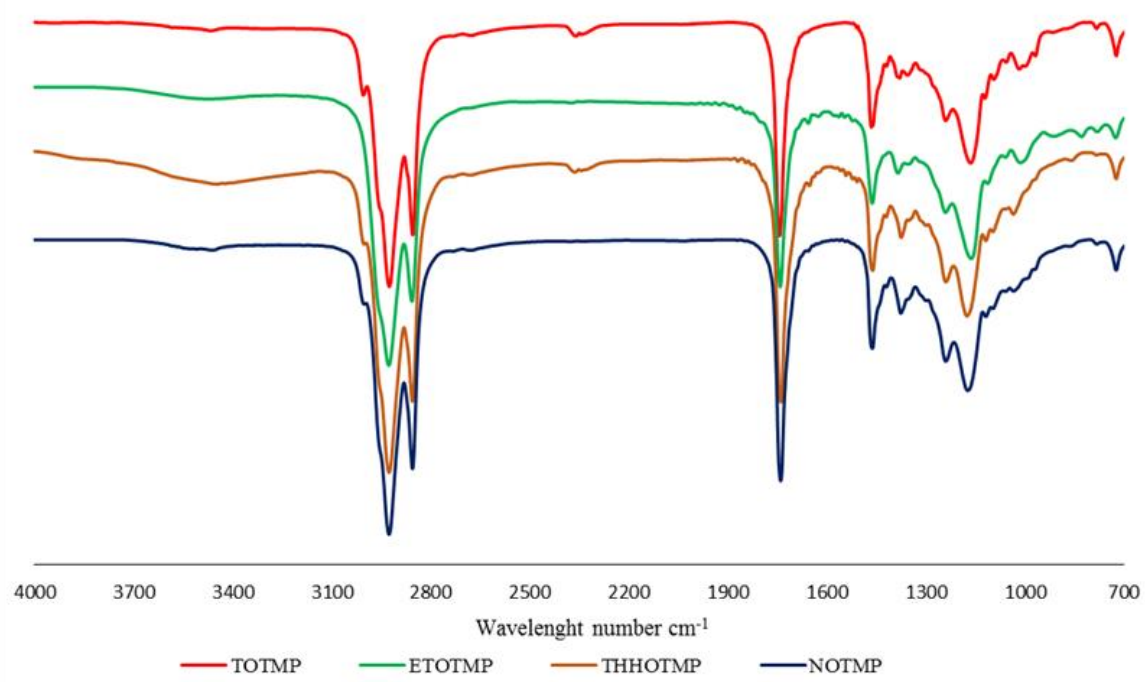

Figure 2. FTIR spectra of compounds (1-4).

\subsection{Lubrication properties analysis.}

The ability of a substance to remain as a liquid at low temperatures is an important attribute for a number of industrial materials, such as biolubricants, surfactants, and fuels.

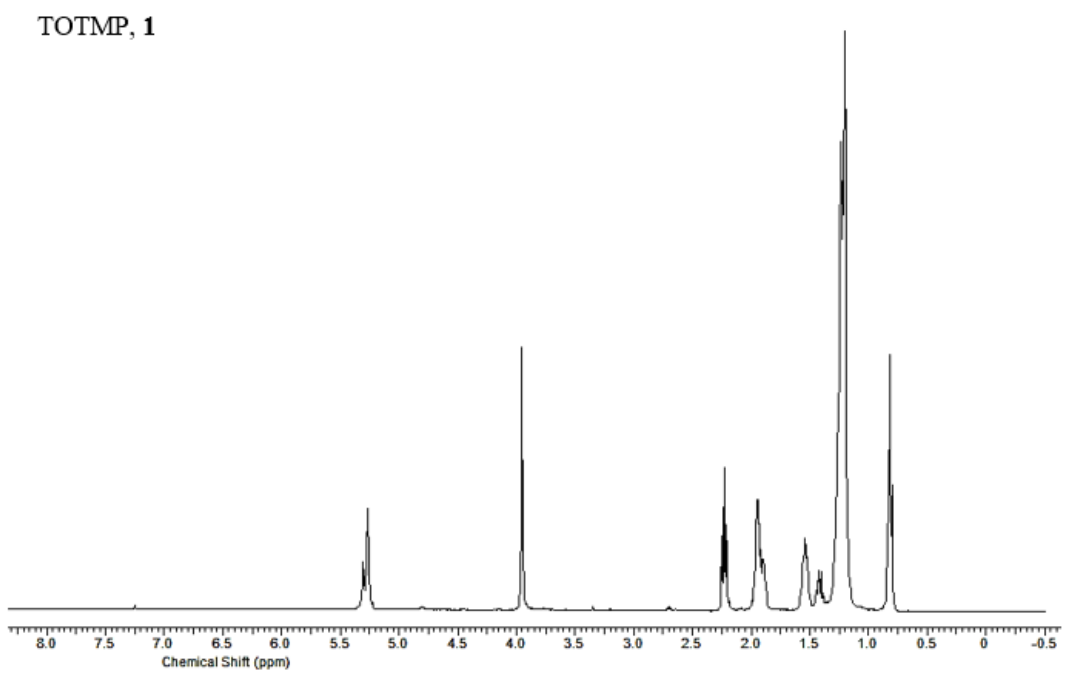



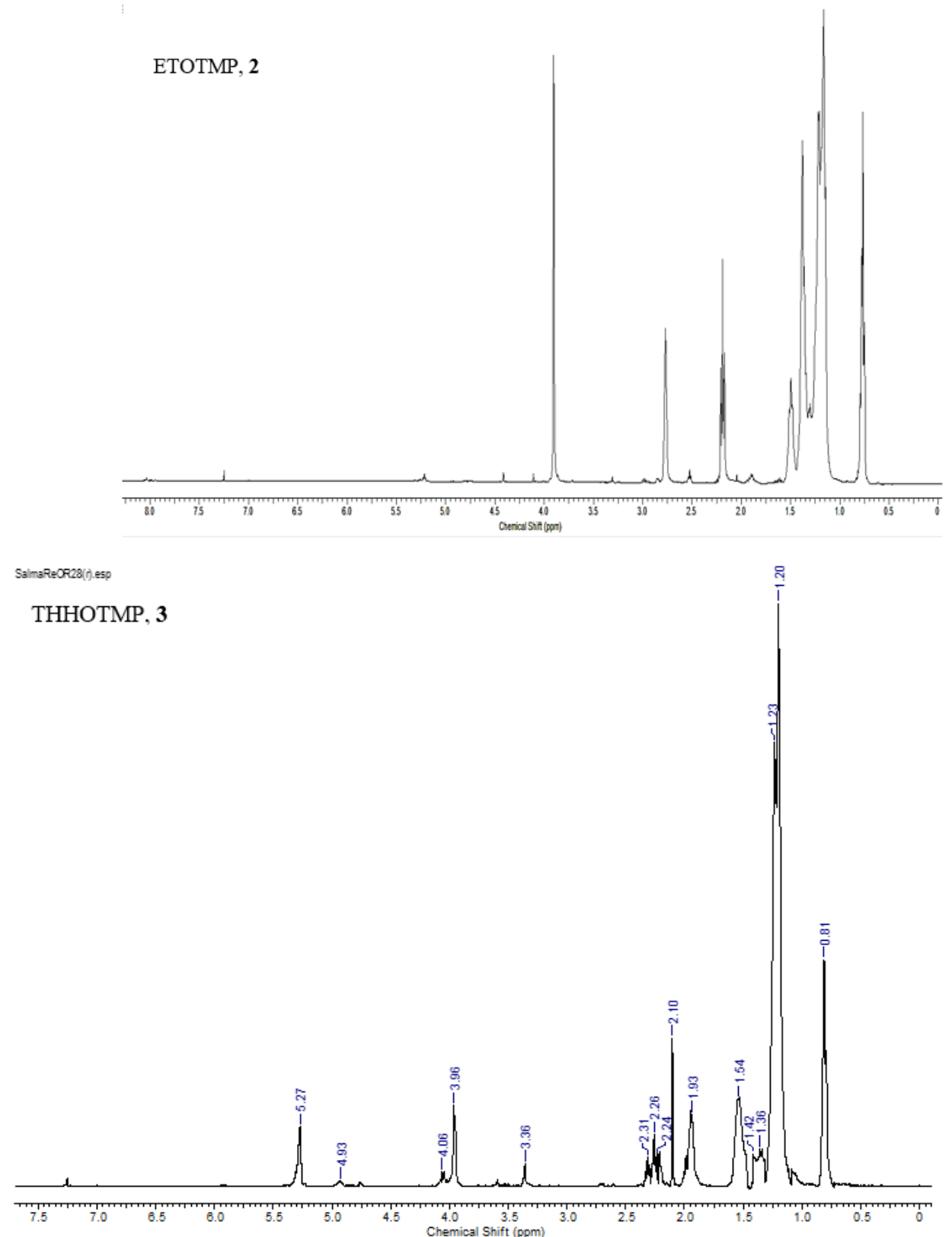

SalrmoR11(r).emp

NOTMP, 4

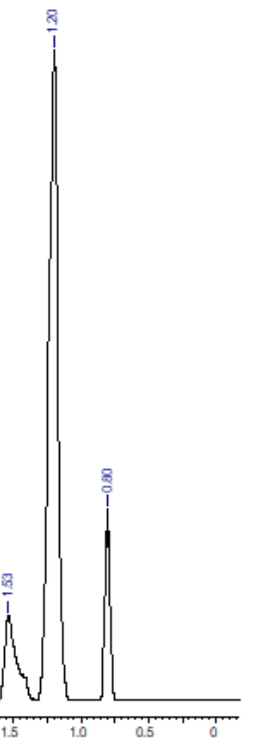

Figure 3. ${ }^{1} \mathrm{H}$ NMR spectra of compounds (1-4). 
The pour point is the lowest temperature where the samples perpetuate in liquid form. Biolubricant oils that are applied in the machine working at cold temperate should possess low PP to avoid solidification. Solidification occurs at low temperatures due to the uniform stacking of the bent triglyceride backbone [25]. From this study, the attachment of the ester side chain of OA at the 9 and 10 positions of the fatty acid chain of TMP to replace the hydroxyl group improved the pour point significantly. For compound THHOTMP (3) has a PP at $-22^{\circ} \mathrm{C}$, while after esterification of $\alpha$-hydroxyls group with another OA, the PP of compound NOTMP (4) gain much better, which is $-34^{\circ} \mathrm{C}$. Therefore, it can be concluded that the presence of a large branching group at the mid-point of a fatty acid chain from the backbone of TMP triggers a steric hindrance to slow the crystallization process. Table 1 shows the lubrication properties of the synthesized compounds (1-4).

The FP refers to the lowest temperature at which lubricant must be heated before it vaporizes. This property is useful to determine the volatility and flammability of materials. Lubricants should have a high flash point to ensure safe operation and minimum volatilization at the maximum operating temperature. The FP is used to describe biolubricants that are not normally used as fuels [4]. The FP is also utilized to determine the type of transportation used and storage temperature that it acquires. Biolubricant producers use FP to discover potential product contamination. Any biolubricant that shows a low FP will be suspected for contamination with volatile products and usually needs special precautions for safe handling [26]. The usability of a biolubricant is limited by its FP at high temperatures. Table 1 shows that NOTMP (4) has the higher FP $\left(320^{\circ} \mathrm{C}\right)$ due to the increase in branch length and carbon chain in the NOTMP structure, which will increase its molecular weight.

The efficiency of the biolubricant in reducing friction and wear is strongly affected by its viscosity. Theoretically, the viscosity will decrease when the temperature increases. Uses of biolubricants in industrial applications are based on their kinematic viscosity (KV). For example, the $\mathrm{KV}$ from 3.8 to $20 \mathrm{cSt}$ at $100^{\circ} \mathrm{C}$ are suitable for engine oil, while from $35.2 \mathrm{cSt}$ and higher are demanded automotive gear oil [27]. VI highlights how the biolubricant viscosity changes with the variation in temperature [9]. A low VI represents relatively large changes of kinematic viscosity induced by changes in temperature. On the other hand, a high viscosity index indicates that kinematic viscosity is largely constant over a wide temperature range [10]. Table 1 shows that the compound NOTMP (4) has the higher VI value (237) and increases the molecular weight and increases the number of ester groups.

Oxidation is a chemical reaction that occurs when the biolubricant combines with oxygen. Oxidation stability indicates the resistance of biolubricant and fuel to withstand oxidation. Pressure differential scanning calorimetry (PDSC) is an effective tool for measuring oxidative stability by determining the OST of a biolubricant in an accelerated mode [28]. The OST $\left({ }^{\circ} \mathrm{C}\right)$ is defined as the temperature at which the oxidation rate increased sharply, observed, and obtained from the tangent line's extrapolation on the steepest slope of the plot of the plot exothermic reaction heat flow versus temperature. A high OST would suggest high oxidative stability of the biolubricant [29]. The synthesized dicarboxylate esters were scanned to measure their OST using PDSC. The results show that ETOTMP (2) showed oxidative stability (OT) at $201^{\circ} \mathrm{C}$ while THHOTMP (3) OT was at $171^{\circ} \mathrm{C}$. This low oxidative stability is due to the unsaturated fatty acids at 9 or 10 position of a fatty acid chain of THHOTMP. Furthermore, the hydroxyl group that present after the opening of the oxirane ring affects the stability of the biolubricant. Hydroxyl groups tend to interact (hydrolyzed) and dramatically affect the oxidative stability of the biolubricant [25]. After the esterification reaction of the $\alpha$-hydroxyl 
with OA to produce NOTMP (4), the oxidative increase to $172^{\circ} \mathrm{C}$. From Table 1, we can see that the performance of oxidative stability of TOTMP (1) and ETOTMP (2) was high compare to THHOTMP (3) and NOTMP (4). This is due to increasing unsaturated content to the structure after the addition of long-chain monounsaturated fatty acid to the biolubricants core. Long chains have more accessible sites prone to oxidation, making them more susceptible to cleavage than short-chain [30]. Figure 5 shows the oxidative stability temperature (OST) of the compounds (1-4).

Table 1. Lubrication properties and yield (\%) of compounds (1-4).

\begin{tabular}{|c|c|c|c|c|c|c|c|c|c|}
\hline \multirow{2}{*}{$\begin{array}{l}\text { Comp. } \\
\text { No. }\end{array}$} & \multirow{2}{*}{$\mathbf{P P}\left({ }^{\circ} \mathbf{C}\right)$} & \multirow{2}{*}{ FP $\left({ }^{\circ} \mathbf{C}\right)$} & \multirow{2}{*}{$\begin{array}{l}\mathbf{K V} @ \mathbf{4 0} \\
{ }^{\circ} \mathbf{C}\end{array}$} & \multirow{2}{*}{$\begin{array}{l}\text { KV @ } \\
100^{\circ} \mathbf{C}\end{array}$} & \multirow{2}{*}{ VI } & \multirow{2}{*}{$\begin{array}{l}\text { OST } \\
\left({ }^{\circ} \mathbf{C}\right)\end{array}$} & \multicolumn{2}{|c|}{ FC } & \multirow{2}{*}{$\begin{array}{l}\text { Yield } \\
(\%)\end{array}$} \\
\hline & & & & & & & $40^{\circ} \mathrm{C}$ & $100^{\circ} \mathrm{C}$ & \\
\hline 1 & $-55 \pm 3$ & $280 \pm 3$ & $45.91 \pm 2$ & $10.54 \pm 3$ & $229 \pm 3$ & $185 \pm 2$ & $0.22 \pm 0.01$ & $0.24 \pm 0.03$ & 98 \\
\hline 2 & $-20 \pm 1$ & $300 \pm 5$ & $77.03 \pm 3$ & $16.89 \pm 2$ & $218 \pm 1$ & $201 \pm 3$ & $0.31 \pm 0.02$ & $0.34 \pm 0.01$ & 72 \\
\hline 3 & $-22 \pm 3$ & $250 \pm 2$ & $388.25 \pm 1$ & $43.20 \pm 3$ & $167 \pm 2$ & $171 \pm 1$ & $0.26 \pm 0.01$ & $0.33 \pm 0.01$ & 90 \\
\hline 4 & $-34 \pm 2$ & $320 \pm 1$ & $224.34 \pm 1$ & $37.20 \pm 1$ & $237 \pm 1$ & $172 \pm 2$ & $0.25 \pm 0.01$ & $0.23 \pm 0.01$ & 95 \\
\hline
\end{tabular}

\subsection{Tribological and rheological properties.}

The type of biolubricant is normally identified based on the biolubricant's tribological properties. The presence of polar groups in the ester structure made it amphiphilic in nature, therefore allowing it to be used as boundary lubricants. The higher the biolubricant polarity, the higher the possibility that it will reduce wear [7].
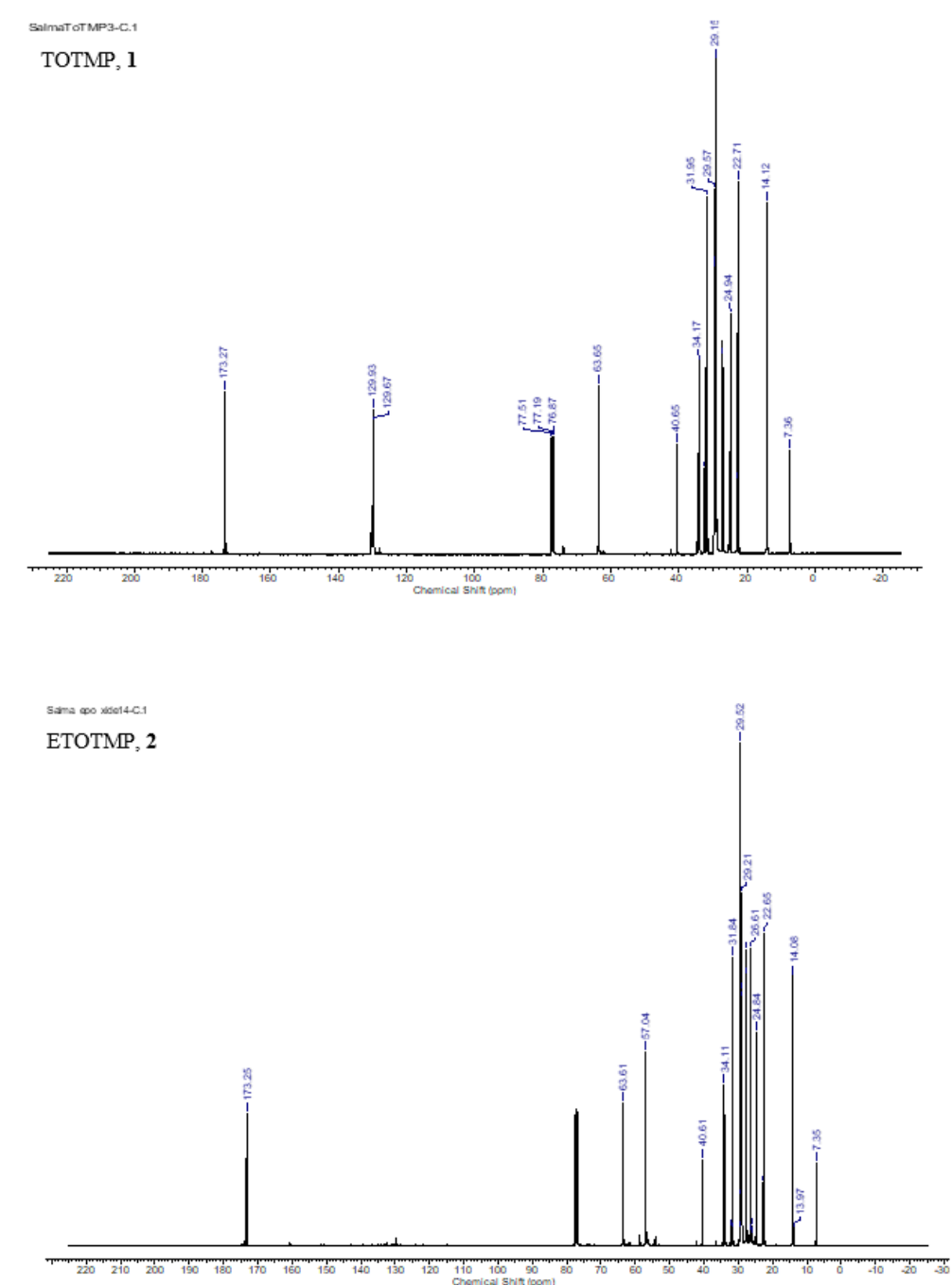


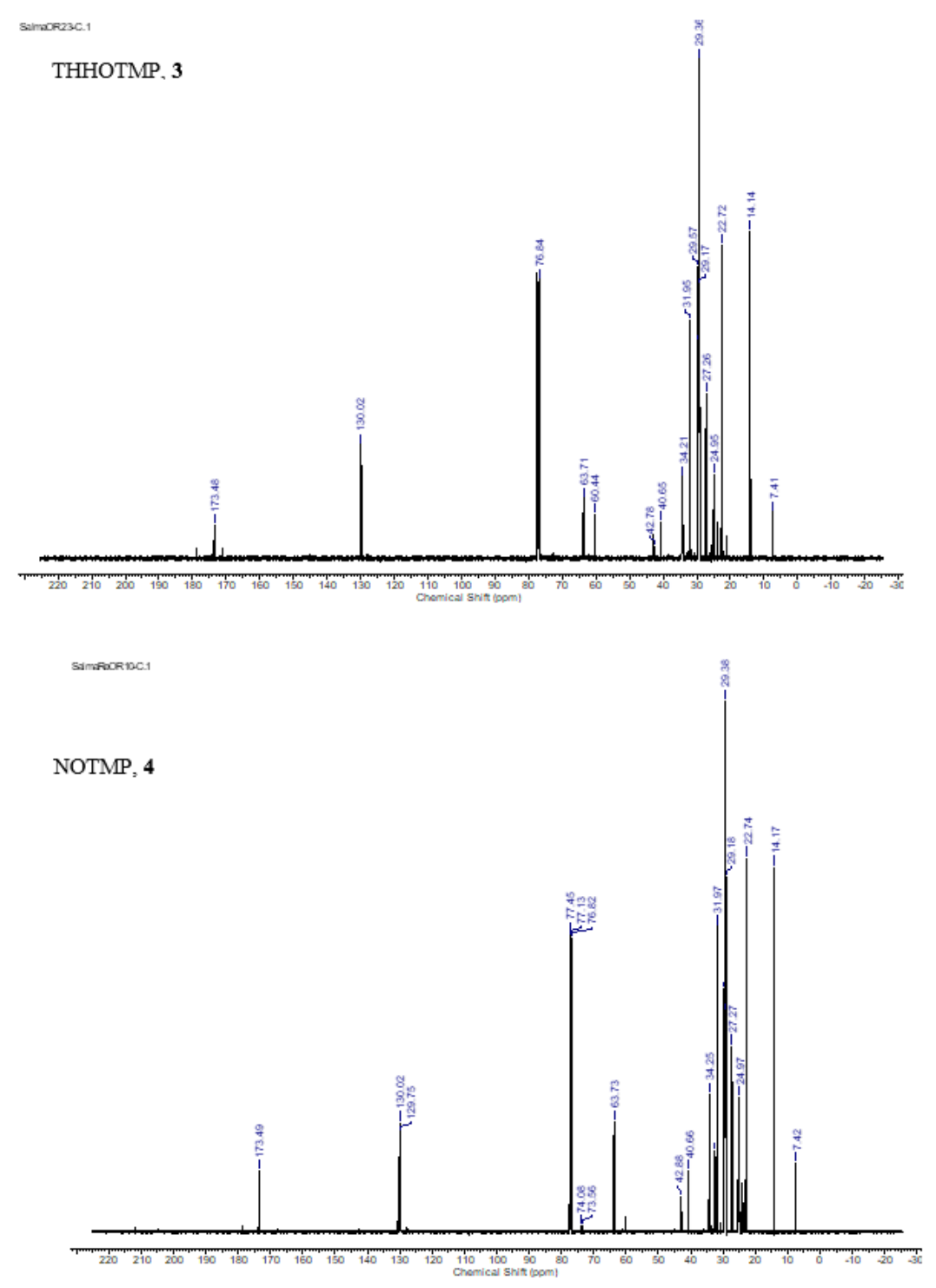

Figure 4. ${ }^{13} \mathrm{C}$ NMR spectra of compounds (1-4).

Biolubricants from plant oils consist of straight-chain carbon with polar end groups, which give them good lubricity. According to Salih et al. (2013) [31], these polar end groups reduce the friction coefficient (FC) because they adsorb onto metallic surfaces and decrease surface energy. Tribological properties as FC values for the synthesized compounds (1-4) are shown in Table 1.

It can be noted that the hyperbranched compound NOTMP (4) with high molecular weight and high VI exhibit low values of FC at 40 and $100{ }^{\circ} \mathrm{C}$ which indicates that the product obtained had a better quality in terms of tribological properties. The low FC values were attributed to the carbon chain-length and the high polarity of NOTMP. Syahrullail et al. (2013) [32] stated that the long carbon chain of fatty esters and the presence of polar groups in the structure of biolubricant make it amphiphilic, therefore allows it to be used as both boundary and hydrodynamic lubricants. Figure 6 shows the FC for the compounds (1-4).

The classification of the rheological property of fluids depends on the relation between the shear stress $(\tau)$ and shear rate $(\gamma)$; when the relation is linear as the shear rate increases, this means that fluids can be classified as a Newtonian fluid, However, when the relation is curved as the shear rate increases, the fluids are classified as non-Newtonian fluid [33, 34]. As shown in Figure 7, the relation between the shear stress $(\tau)$ and shear rate $(\gamma)$ is linear as the shear rate increases. This means that under such conditions, the synthesized compounds (1-4) can be 
considered as a Newtonian fluid model, where the viscosity does not change as the shear stress increases. This result is supported by a viscosity versus shear rate graph showing that the viscosity is constant and unchanged in the 20-100s.
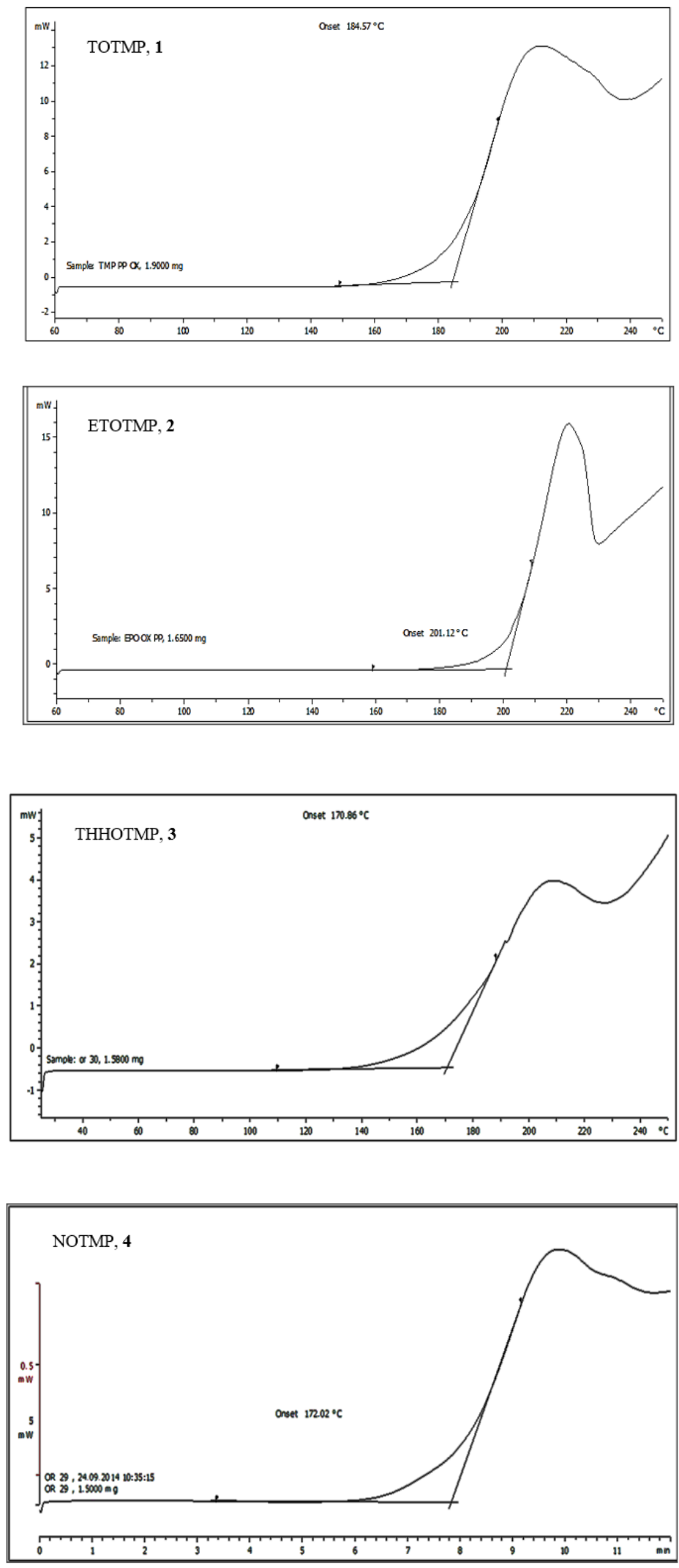

Figure 5. PDSC of Oxidative stability temperatures (OST, $\left.{ }^{\circ} \mathrm{C}\right)$ of compounds (1-4). 

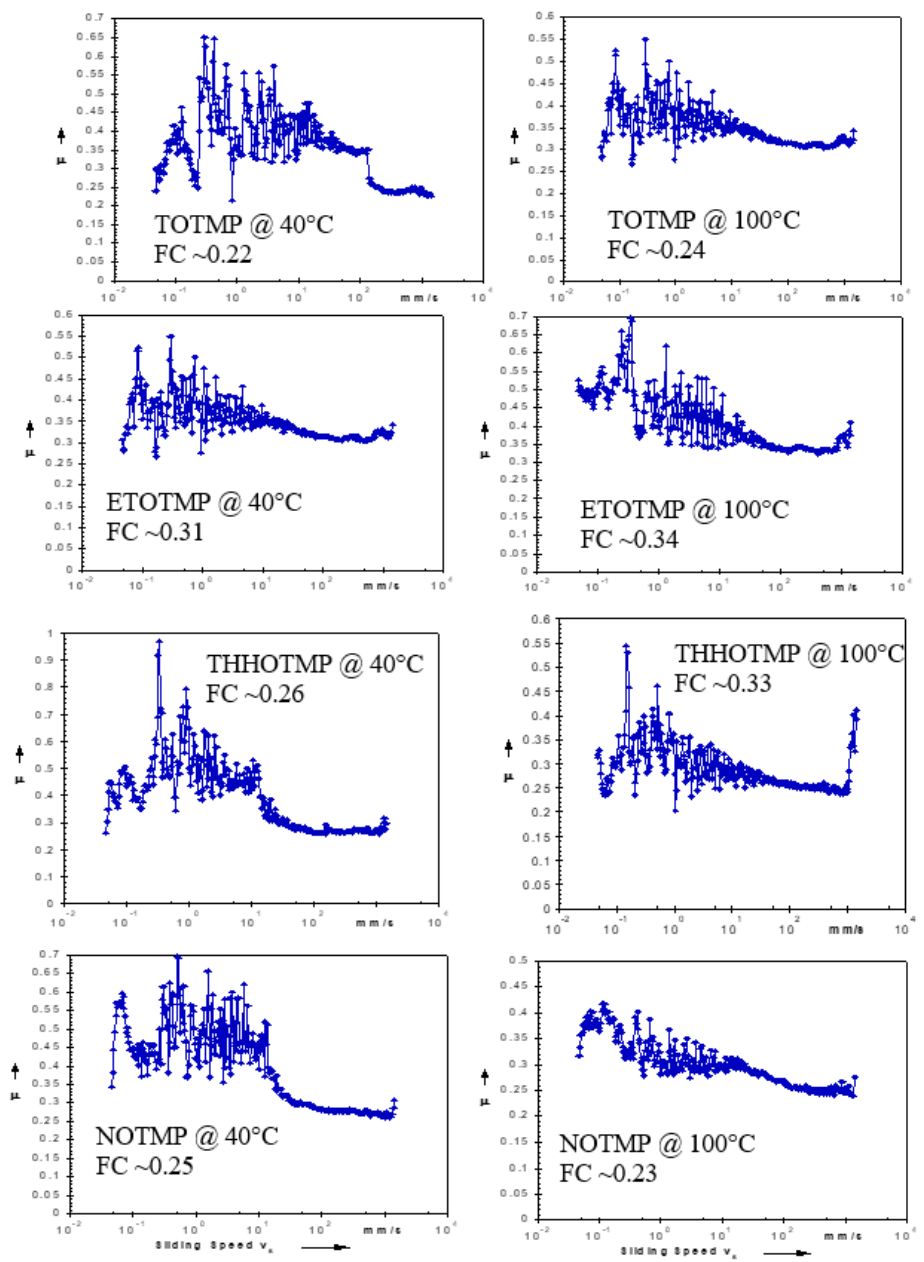

Figure 6. Friction coefficients of compounds (1-4) at 40 and $100{ }^{\circ} \mathrm{C}$.
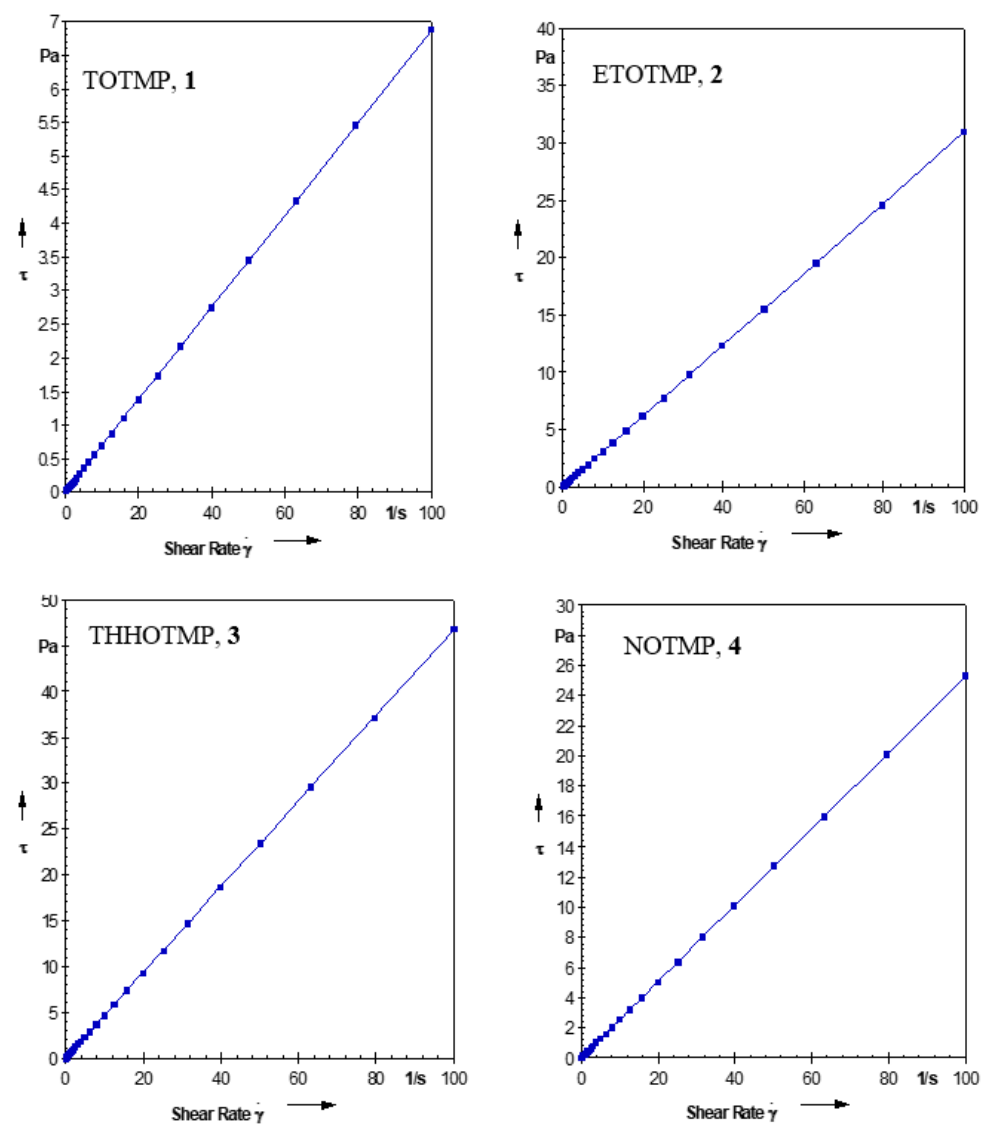

Figure 7. Shear stress $(\tau)$ vs shear rate $(\gamma)$ plots of compounds (1-4). 


\section{Conclusions}

In this study, compounds (1-4) were successfully synthesized by epoxidation, oxirane ring-opening, and esterification reactions. The results showed that the synthesized compounds have an acceptable performance as a biolubricant. They have good friction coefficient properties, high viscosity index, high flash point, high oxidative stability temperature, and significantly low pour point. These qualities demonstrated that they are promising potential to be used as commercial biolubricants without additives.

\section{Funding}

This research was funded by UNIVERSITI KEBANGSAAN MALAYSIA, grant numbers DPP-2014-058 and UKM-AP2011-17.

\section{Acknowledgments}

The authors acknowledge the direct contributions of the support staff from the Department of Chemical Sciences, Faculty of Science and Technology, Universiti Kebangsaan Malaysia and Ministry of Higher Education (MyBrain15).

\section{Conflicts of Interest}

The authors declare no conflict of interest.

\section{References}

1. Karmakar, G.; Ghosh, P.; Sharma, B.K. Chemically modifying vegetable oils to prepare green lubricants. Lubricants 2017, 5, 1-17, https://doi.org/10.3390/lubricants5040044.

2. Bahadi, M.; Yusoff, M.F.; Salimon, J.; Derawi, D. Optimization of response surface methodology by Doptimal design for alkaline hydrolysis of crude palm kernel oil. Sains Malaysiana 2020, 49, 29-41, https://doi.org/10.17576/jsm-2020-4901-04.

3. Afifah, A.N.; Syahrullail, S.; Wan Azlee, N.I.; Che Sidik, N.A.; Yahya, W.J.; Abd Rahim, E. Biolubricant production from palm stearin through enzymatic transesterification method. Biochem Eng J 2019, 148, 178184, https://doi.org/10.1016/j.bej.2019.05.009.

4. Fadzel, F.M.; Salimon, J.; Derawi, D. Biolubricant production from palm stearin fatty acids and pentaerythritol. Malaysian J Chem 2019, 21, 50-63.

5. Kushairi, A.; Ong-Abdullah, M.; Nambiappan, B.; Hishamuddin, E.; Bidin, M.N.I.Z.; Ghazali, R.; Subramaniam, V.; Sundram, S.; Parveez, G.K.A. Oil palm economic performance in Malaysia and r\&d progress in 2019. J Oil Palm Res 2020, 32, 159-190, https://doi.org/10.21894/jopr.2019.0026.

6. Nor, N.M.; Derawi, D.; Salimon, J. Esterification and evaluation of palm oil as biolubricant base stock. Malaysian J Chem 2019, 21, 28-35.

7. Alfieri, A.; Imperlini, E.; Nigro, E.; Vitucci, D.; Orrù, S.; Daniele, A.; Buono, P.; Mancini, A. Effects of plant oil interesterified triacylglycerols on lipemia and human health. Int J Mol Sci 2018, 19, 1-11, https://doi.org/10.3390/ijms19010104.

8. Annisa, A.N.; Widayat, W. A Review of bio-lubricant production from vegetable oils using esterification $\begin{array}{llllll}\text { transesterification process. MATEC Web Conf 2018, 156, } & \text { 1-7, }\end{array}$ https://doi.org/10.1051/matecconf/201815606007.

9. Liu, C.; Meng, Z.; Chai, X.; Liang, X.; Piatko, M.; Campbell, S.; Liu, Y. Comparative analysis of graded blends of palm kernel oil, palm kernel stearin and palm stearin. Food Chem 2019, 286, 636-643, https://doi.org/10.1016/j.foodchem.2019.02.067

10. Moreira, D.R.; Chaves, P.O.B.; Ferreira, E.N.; Arruda, T.B.M.; Rodrigues, F.E.A.; Neto, J.F.C.; Petzhold, C.L.; Maier, M.E.; Ricardo, N.M.P. . Moringa polyesters as eco-friendly lubricants and its blends with naphthalenic lubricant. Ind Crops Prod. 2020, 158, 112937, https://doi.org/10.1016/j.indcrop.2020.112937

11. Nor, N.M.; Salih, N.; Salimon, J. Optimization of the ring opening of epoxidized palm oil using D-optimal design. Asian J Chem 2021, 33, 67-75, https://doi.org/10.14233/ajchem.2021.22938.

12. Sarno, M.; Iuliano, M.; Cirillo, C. Optimized procedure for the preparation of an enzymatic nanocatalyst to produce a bio-lubricant from waste cooking oil. Chem Eng $J$ 2019, 377, 120273, https://doi.org/10.1016/j.cej.2018.10.210. 
13. Shahabuddina, M.; Mofijur, M.; Kalam, M.A.; Masjuki, H.H.. Study on the friction and wear characteristics of bio-lubricant synthesized from second generation Jatropha methyl ester. Tribol Ind 2020, 42, 41-49, https://doi.org/10.24874/ti.2020.42.01.04

14. Bahadi, M.; Yusoff, M.F.; Salimon, J.; Japir A.W.; Derawi, D. Optimization of low-temperature methanol crystallization for unsaturated fatty acids separation from crude palm fatty acids mixture using response surface methodology. Asian J Chem 2019, 31, 1617-1625, https://doi.org/10.14233/ajchem.2019.21974.

15. Bahadi, M.; Yusoff, M.F.; Salimon, J.; Derawi, D. Optimization of response surface methodology by Doptimal design for synthesis of food-grade palm kernel based biolubricant. Ind Crops Prod 2019, 139, 1-12, https://doi.org/10.1016/j.indcrop.2019.06.015.

16. ASTM D 2270-93. Standard practice for calculating viscosity index from kinematic viscosity at 40 and $100^{\circ} \mathrm{C}$. ASTM, USA, West Conshohocken, PA, 2005.

17. ASTM D 97-05. Standard test method for pour point of petroleum products. ASTM, USA, West Conshohocken, PA, 2005.

18. ASTM D 56-79. Standard test method for flash and fire points by Cleveland open cup tester. ASTM, USA, West Conshohocken, PA, 2005.

19. ASTM D4172-94. Standard test method for wear preventive characteristics of lubricating fluid (four-ball method). ASTM, USA, West Conshohocken, PA, 2011.

20. Bahadi, M.; Salimon, J.; Japir, A.W. The physicochemical and thermal properties of Malaysian high free fatty acid crude palm oil. AIP Conf Proceed 2016, 1784, 1-6, https://doi.org/10.1063/1.4966740.

21. Coussot, P.; Tocquer, L.; Lanos, C.; Ovarlez, G. Macroscopic vs. local rheology of yield stress fluids. $J$ Nonnewton Fluid Mech 2009, 158, 85-90, https://doi.org/10.1016/j.jnnfm.2008.08.003.

22. Borugadda, V.B.; Goud, V.V. Physicochemical and rheological characterization of waste cooking oil epoxide and their blends. Waste Biomass Valorization 2016, 7, 23-30, https://doi.org/10.1007/s12649-0159434-8.

23. Pavia, D.L.; Lampman, G.M.; Kriz, G.S. Introduction to spectroscopy. $4^{\text {th }}$ ed., Thomson Learning, Inc., USA, 2010.

24. Japir, A.A.W.; Salimon, J.; Derawi, D.; Yahaya, B.H.; Jamil, M.S.M.; Yusop M.R. Optimization of methanol crystallization for highly efficient separation of palmitic acid from palm fatty acid mixture using response surface methodology. Grasas y Aceites 2017, 68, 1-15, https://doi.org/10.3989/gya.0552171.

25. Cecilia, J.A.; Plata, D.B.; Saboya, R.M.A.; de Luna, F.M.T.; Cavalcante, C.L.; Rodríguez-Castellón, E. An overview of the biolubricant production process: Challenges and future perspectives. Processes 2020, 8, 124, https://doi.org/10.3390/pr8030257.

26. Japir, A.A.W., Salimon, J., Derawi, D., Yahaya, B.H., Bahadi, M., Al-Shuja'A, S.; Yusop, M.R. A highly efficient separation and physicochemical characteristics of saturated fatty acids from crude palm oil fatty acids mixture using methanol crystallisation method. OCL - Oilseeds and fats, Crops and Lipids 2018, 25, A203, https://doi.org/10.1051/ocl/2018003.

27. Chan, C.H.; Tang, S.W.; Mohd, N.K.; Lim, W.H.; Yeong, S.K.; Idris, Z. Tribological behavior of biolubricant base stocks and additives. Renew Sust Energy Rev 2018, 93, 145-157, https://doi.org/10.1016/j.rser.2018.05.024.

28. Devi, A.; Khatkar, B.S. Physicochemical, rheological and functional properties of fats and oils in relation to cookie quality: A review. J Food Sci Technol 2016, 53, 3633-3641, https://doi.org/10.1007/s13197-0162355-0.

29. Folayan, A.J.; Anawe, P.A.L., Aladejare, A.E., Ayeni, A.O. Experimental investigation of the effect of fatty acids configuration, chain length, branching and degree of unsaturation on biodiesel fuel properties obtained from lauric oils, high-oleic and high-linoleic vegetable oil biomass. Energy Rep 2019, 5, 793-806, https://doi.org/10.1016/j.egyr.2019.06.013.

30. dos Santos, L.K.; Hatanaka, R.R.; de Oliveira, J.E.; Flumignan, D.L. Production of biodiesel from crude palm oil by a sequential hydrolysis /esterification process using subcritical water. Renew Energy 2019, 130, 633-640, https://doi.org/10.1016/j.renene.2018.06.102.

31. Salih, N.; Salimon, J.; Yousif, E.; Abdullah, B.M. Biolubricant basestocks from chemically modified plant oils: Ricinoleic acid based-tetraesters. Chem Cent J 2013, 7, 128-140, https://doi.org/10.1186/1752-153x-7128.

32. Syahrullail, S.; Hariz, M.A.M.; Abdul Hamid, M.K.; Abu Bakar, A.R. Friction characteristic of mineral oil containing palm fatty acid distillate using four ball tribo-tester. Procedia Eng 2013, 68, 166-171, https://doi.org/10.1016/j.proeng.2013.12.163.

33. Xiong, Z.; Fu, F.; Li, X.; Li, Y. Preparation of an environmentally friendly emulsion-type lubricant based on crude rice bran wax. Petroleum 2019, 5, 77-84, https://doi.org/10.1016/j.petlm.2018.09.002

34. Gul, M.; Masjuki, H.H.; Kalam, M.A.; Zulkifli, N.W.M.; Mujtaba, M.A. A Review: Role of fatty acids composition in characterizing potential feedstock for sustainable green lubricants by advance transesterification process and its global as well as Pakistani prospective. Bioenergy Res 2020, 13, 1-22, https://doi.org/10.1007/s12155-019-10040-7. 